\title{
Desenvolvimento de cursos interativos, adaptativos e gamificados com Smart Sparrow
}

\author{
Silvino Marques da Silva Junior ${ }^{1}$ \\ ${ }^{1}$ Campus Floriano - Instituto Federal do Piauí (IFPI) \\ CEP - 64.808-753 - Floriano - PI - Brazil \\ silvinomarquesjregmail.com
}

\begin{abstract}
This paper aims to present a technological tool, with multimedia resources, interactive and easy to use, that be enjoyable and can arouse the interest of students, contributing to learning. It is expected with this paper will encourage the use of innovative methodologies and technology in the service of education.
\end{abstract}

Resumo. Este trabalho tem por objetivo apresentar uma ferramenta tecnológica com recursos multimídia, interativa e de fácil manuseio, que seja agradável e possa despertar o interesse dos alunos, contribuindo para a aprendizagem. Espera-se com este artigo incentivar a utilização de metodologias inovadoras e da tecnologia a serviço da educação.

\section{Introdução}

As características dos jovens atuais mostram que existe nova forma de aprender, através de um mundo digital, mais atrativo e que possibilita a utilização de todas as ferramentas disponíveis pelos chamados nativos digitais (CARVALHO; OLIVEIRA; SILVA, 2015).

Conforme Mattar (2010), o aprendizado desses alunos não segue uma estrutura linear, como era antigamente, "eles possuem mentes hipertextuais" (p.10). Aprendem explorando, tentando, mexendo, não leem manuais, aprendem compartilhando.

Muitos desses discentes chegam a sala de aula em um ritmo digital e se deparam com professores imigrantes digitais, muitas vezes, não familiarizados com as TDIC's, e a escola parece estar em um mundo alheio ao deles. (PRENSKY, 2001).

É preciso incentivar os alunos a utilizarem as tecnologias de forma inovadora e produtiva, promovendo experiências criativas e conduzindo esses jovens à novas e infinitas possibilidades de aprender (RESNICK, 2006).

O resultado positivo do uso das ferramentas computacionais, citado por vários autores da literatura, incita a utilização de ferramentas tecnológicas que se proponham a facilitar o aprendizado dos alunos de maneira lúdica e atrativa e consequentemente minimizar as dificuldades encontradas pelos discentes no aprendizado de conceitos complexos.

\section{Métodos}

Este trabalho descreve uma ferramenta tecnológica existente que permite a criação de atividades e-Learning ricas, interativas, altamente visuais e adaptativas. A Smart 
VII Congresso Brasileiro de Informática na Educação (CBIE 2018)

Anais dos Workshops do VII Congresso Brasileiro de Informática na Educação (WCBIE 2018)

Sparrow é uma startup criada no Grupo de Pesquisas de Ensino Adaptativo da University of New South Wales, na Austrália. Ela foi criada em 2010, e contém um módulo chamado Adaptive eLearning Platform - AeLP.

Para realização da pesquisa, estudamos artigos publicados anteriormente com a temática das ferramentas computacionais, da adaptatividade e gamificação como Bardini et al (2017) e Dermeval e Bittencourt (2017). Analisamos a ferramenta citada e na seção 3 são apresentados explicações, telas e funcionalidades. Na seção 4 apresentamos a análise dos questionários de avaliação realizada por alunos do ensino médio.

\section{Ferramenta Smart Sparrow}

Cursos criados pelo AeLP podem conter características de interatividade, adaptatividade e gamificação, fornecendo um ambiente para atender às necessidades individuais de aprendizagem dos alunos, através de exercícios interativos, feedback adaptativo e scores ou pontuação.

A gamificação pode ser utilizada para promover a aprendizagem, modificando um conteúdo comumente apresentado em uma aula tradicional por meio da inclusão de elementos de jogos que criam uma oportunidade de aprendizagem gamificada no formato de um jogo. (FIGUEIREDO, 2015).

O conteúdo da disciplina pode ser percorrido pelo aluno de forma variada, dependendo da capacidade de resolver os exercícios propostos. Desta forma, o ritmo de aprendizagem se adapta ao perfil do aluno, podendo ser mais rápido ou mais lento, dependendo da maior ou menor facilidade em aprender os conceitos.

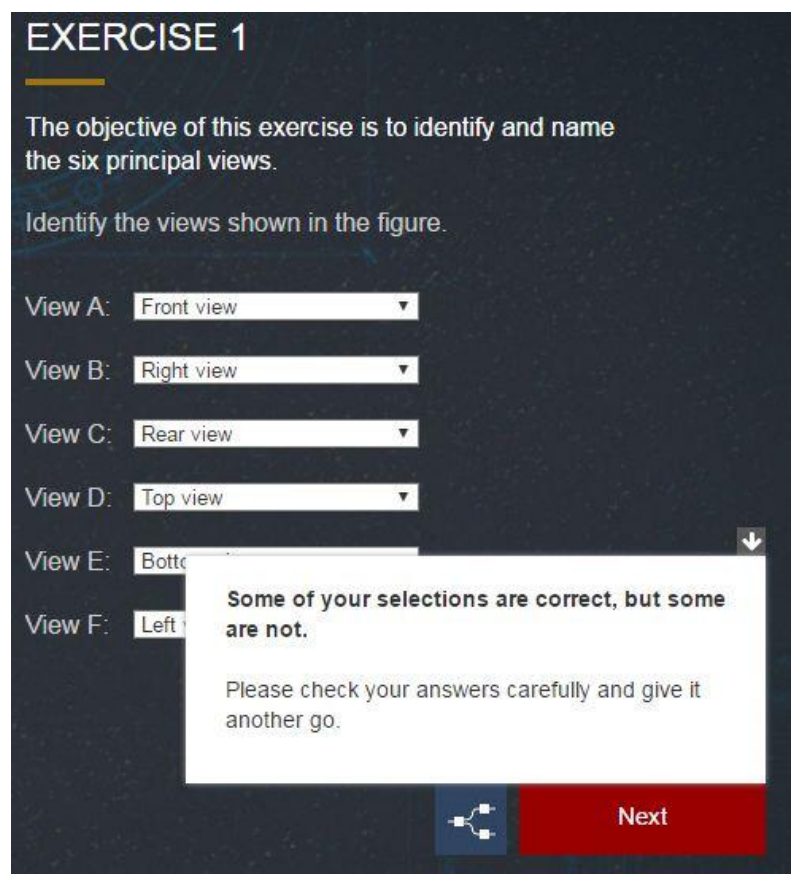

Figura 1: Tela com Feedback de Erro

Existem duas características utilizadas para prover a adaptação: a) o número de tentativas e erros (Figura 1) e b) o tempo dispensado a resolver uma atividade. Essas 
VII Congresso Brasileiro de Informática na Educação (CBIE 2018)

Anais dos Workshops do VII Congresso Brasileiro de Informática na Educação (WCBIE 2018)

características são utilizadas para adaptar a navegação e a apresentação do ambiente. A gamificação é implementada através de scores, que é uma recompensa quantitativa que está relacionada à atividades e comportamentos.

Além de conteúdos textuais e vídeos, a ferramenta também possui conteúdos dinâmicos que possibilitam ao aluno interagir com o ambiente, como é o caso da Figura 2 , que permite ao aluno testar os conhecimentos adquiridos em telas anteriores.



Figura 2: Tela de Exercícios

Atividades como a da Figura 2, em que o usuário deve selecionar adequadamente os itens de acordo com cada figura, permitem ao aluno desenvolver novos esquemas mentais de forma gradativa que o habilita a chegar à solução de outros problemas a partir de situações equivalentes.

Caso o aluno tenha dificuldade em entender a lógica utilizada para resolver o problema proposto e supere o número de três tentativas com erro, o sistema identifica, emite um feedback automático e o redireciona a páginas com explicações adicionais e a correção do exercício proposto.

Ao chegar ao fim do curso, o aluno recebe um aviso de que concluiu as atividades e o resultado final atingido em scores, além de recomendações acerca de seu desempenho.

\section{Resultados}

Nesse primeiro momento, foi realizada a coleta de dados com uma amostra de 15 (quinze) alunos do ensino médio integrado ao técnico em Informática que se dispuseram a utilizar a ferramenta e avaliar o seu funcionamento. Os resultados obtidos, permitiram verificar a opinião dos alunos em relação ao curso e aos conceitos de interatividade, adaptatividade e gamificação propostos na ferramenta.

O questionário foi constituído de 06 (seis) perguntas e respostas cujas numerações variavam de 1 a 5 , onde: $1=$ péssimo, $2=$ regular, $3=$ bom, $4=$ muito bom, 5 = excelente. O resultado da primeira pergunta ("A ferramenta possui características de interatividade?") comprovou essa característica por $46,7 \%$ dos alunos, que assinalaram excelente e por $26,7 \%$, que assinalaram muito bom; já outros $20 \%$ assinalaram bom e $6,7 \%$ regular.

$\mathrm{Na}$ segunda pergunta, foi questionado se o conteúdo é bem explicativo, $60 \%$ dos alunos assinalaram excelente; $13,3 \%$ igualmente para muito bom, bom e regular. A 
VII Congresso Brasileiro de Informática na Educação (CBIE 2018)

Anais dos Workshops do VII Congresso Brasileiro de Informática na Educação (WCBIE 2018)

terceira questão abordava a capacidade de a ferramenta se adaptar as respostas fornecidas pelo aluno; nesta $66,7 \%$ avaliaram como excelente, outros $26,7 \%$ bom e apenas $6,7 \%$ regular.

Uma das principais questões foi se a característica de gamificação motivou o alunos a buscar o conhecimento e responderem os questionamentos corretamente. Os resultados comprovaram que $73,3 \%$ dos alunos responderam excelente, $20 \%$ muito bom e apenas $6,7 \%$ regular.

\section{Conclusão}

Os discentes atuais, considerados nativos digitais, não mais concebem a aprendizagem como algo estático, passivo e vivem em um mundo altamente "conectado", ou seja, dinâmico, sujeito a mudança e colaborativo. As TDICs com suas características de dinamismo e compartilhamento rápido de informações induz a escola a repensar as metodologias tradicionais de seus professores.

A utilização de ambientes lúdicos e adaptativos são importantes para que as instituições de ensino se adequem a realidade atual dos alunos. Contudo isso, o desenvolvimento e a utilização de ferramentas tecnológicas que despertem o interesse do aluno, auxiliando o aprendizado dos conteúdos tem se tornado item imprescindível no cenário educacional atual.

Almeja-se com este trabalho o incentivo a reflexão acerca de metodologias inovadoras e utilização efetiva da tecnologia a favor da educação. Tornar o aluno mais participativo, motivado e autônomo da sua aprendizagem é um desafio diário a ser conquistado.

\section{Referências}

Bardini, A. et al. Aplicativo Lúdico-Pedagógico para Ensino de Programação e Robótica Educacional. In: Anais dos Workshops do Congresso Brasileiro de Informática na Educação. 2017. p. 222.

Carvalho, C. A.; Oliveira, E. S. G.; Silva, F. T. B. Aprendizagem e Tecnologias Digitais: novas práticas, jovens aprendizes. Colóquio Internacional Educação, Cidadania e Exclusão (CEDUCE), v. 4, 2015.

Dermeval, D.; Bittencourt, I. I. Authoring gamified intelligent tutoring systems. In: Anais dos Workshops do Congresso Brasileiro de Informática na Educação. 2017. p. 14.

Figueiredo, K. Proposta de Gamificação de Disciplinas em um Curso de Sistemas de Informação. In: XIII XI Simpósio Brasileiro de Sistemas de Informação (SBSI 2015).

Mattar, J. Games em educação: como os nativos digitais aprendem. Editora Prentice Hall, 2010. 208p.

Prensky, M. Nativos digitais, imigrantes digitais. On the horizon, v. 9, n. 5, p. 1-6, 2001

Resnick, M. Repensando o aprendizado na era digital. In: Workshop: Scratch e Cricket: Novos ambientes de aprendizagem e de criatividade. Campinas. 2006. 